\title{
Vehicular Pollution in Katmandu Valley
}

\author{
Ramchandra Sapkota \\ Department of Mechanical Engineering, Institute of Engineering, Tribhuvan University, Nepal
}

\begin{abstract}
This paper highlights the issue of vehicular pollution in the Kathmandu valley. Vehicular pollutants include $\mathrm{CO}, \mathrm{HC}$, NOx, Sox, lead and particulate matters which have damaging effects on both human health and ecology. Diesel-driven vehicles emit particulates that are very fine and a large proportion of them are less than 2.5 microns in size, which can penetrate deeper into our lungs. These pollutants are believed to affect the respiratory and cardiovascular systems. Uncontrolled growth of vehicle population, poor transportation infrastructure, traffic congestion, driving patterns and inefficient public transportation systems are major factors in increasing vehicular pollution levels.
\end{abstract}

Key words: Vehicular pollution, vehicle population, Pollutants, transportation infrastructure and PM2.5.

\section{Introduction}

Automobiles play a vital role in the development process of modern society. The automobile industry covers a very large sector of human activities and it is difficult to imagine the world without vehicles. But these same vehicles are major contributors in creating air pollution problems in big cities. As the vehicle fleet continues to grow, pollution problems also grow with an alarming rate.

Topographically, the Kathmandu valley is surrounded by lovely green mountains above which stand huge snow-capped peaks. It has a bowl-like shape and consists of three main cities, Kathmandu, Patan and Bhaktapur, which have great historic, artistic and cultural value.

With the uncontrolled rate of population growth and the concentration of economic activities and other opportunities within the Kathmandu valley, the number of vehicles is also growing very rapidly. The total number of vehicles registered in the Bagmati zone was 2,72,862 in the year $2004 / 05$ and the average growth rate of total vehicles in the decade was $13.44 \%$. The vehicle growth rate data shows that motor bikes had the highest growth rate of $10.62 \%$ and the growth rate of other vehicles like car/ jeep/van, bus, minibus and microbus were $7.38 \%, 8.94 \%, 4.55 \%$ and $6.43 \%$ respectively (Ale, BB).

This rapid rise in vehicle numbers and poor transportation infrastructure are causing serious problems of vehicular pollution in Kathmandu valley which need to be studied so that a detailed series of recommendations can be offered to help policy makers design control programs to reduce vehicular emissions.

\section{Problems and Issues}


High birth rate, migration of people from other parts of the country for opportunities concentrated in the capital and other socio-cultural, geo-political and economical situations are the major causes of rapid population growth in the Kathmandu valley. This uncontrolled growth of population inside the valley creates increasing demand of vehicles for public and private transportation. As a consequence, the number of vehicles has increased vary rapidly which is creating serious pollution problems. Vehicular pollution has become a serious issue in Kathmandu. There is a strong need for a detailed study on vehicular pollution as well as a means to predict the individual \& combined effect of various parameters contributing to the increase of pollution. Focus should be on both types and origins of causes for the growth of vehicular pollution in the Kathmandu valley.

\section{Literature Survey}

Vehicular emission is the major cause of outdoor air pollution in urban areas of Nepal particularly in Kathmandu Valley. The topography of Kathmandu valley is supporting the deterioration in air quality caused by high population growth, more fuel consumption and vehicular and industrial growth. The condition turns more during winter months due to occurrence of temperature inversion that traps pollutants within the valley air basin. During winter (Feb \& Mar) of 1999, about $86.9 \%$ of observed scattering coefficient values were found above $0.210 \mathrm{~km}^{-1}$ which indicates heavy pollution. The average visibilities for Feb \& Mar of 1999 were found to be $14.2 \mathrm{~km}$ and $12.63 \mathrm{~km}$ respectively. The natural way of cleansing the valley atmosphere is the flushing out of the pollutants from valley atmosphere by the prevailing winds. Solar radiation during day time causes vertical dispersion of the pollutants which are then drifted away from the valley by the winds aloft. The study of valley wind since many years back reveals that the wind pattern remains mostly westerly and southwesterly throughout a year. Nagarkot site is free from local air pollution sources but the pollutants originated at Kathmandu Valley are transported to Nagarkot and Banepa, creating severe pollution problems there (Sapkota BK).

If we think at global level, there are approximately 600 million cars, passenger vans, SUVs and light trucks in the world today. Of those about 240 million are found in the United States only. It is a little difficult to then do simple math and say there are 6.76 billion people in the world (according to the US Census Bureau) so 600 million / 6.76 billion = about $9 \%$ of the world population owns a car.

The reason is not all 600 million cars, passenger vans, SUVs and light trucks belong to private citizens. That number includes taxis, police cars, commercially used vehicles like vans and pickup trucks for delivery services, SUVs and cars are used by fire departments, medical services, rental car fleets at airports around the world, and military vehicles. Likewise there are many people who collect cars, and we find households in western nations where it is common to own more than one car. So the percentage of auto ownership globally becomes lower than what shows mathematical calculation.

In developing countries like Brazil, India and China the trend of auto consumption is increasing tremendously. Delhi's registered vehicular population had nearly doubled to 4.5 million from 2.2 million in 1994, registering a growth rate of $10 \%$ per annum. About two-Third of the Motor Vehicles were two-wheelers. 
In 2008 China became the largest auto consuming country in the world, with its citizens buying more cars than people in the United States or Japan. Even more interesting, the number one importer in China is General Motors, with a similar market share in China as an importer that Toyota has in the United States.

In China, Brazil, and India, their population is pushing hard for a more western lifestyle, and they see the car as part of that lifestyle. China and India in particular are spending billions on highway infrastructure. Brazil is interesting as they have largely an ethanol based economy, with cars running largely on alcohol produced from sugarcane. That hasn't come without a price ecologically, namely the slashing and burning of rainforest to create sugarcane fields, and the dangers to the low paid workers who work those fields (this was highlighted well in National Geographic).

In recent years, the vehicle population in China has been increasing sharply, with much of the growth taking place in cities. As a result, serious air pollution problems are beginning to emerge. To address these concerns, China has put together a project with the World Bank to develop a National Action Plan to address motor vehicle pollution. The objective of the project was to assure that by 2010 the air quality levels in China's major cities meet the second class of national standards according to the ninth-five year plan. The total number of motorized vehicles in China, although very low by Western standards, is growing rapidly and has already risen to about 1 million in Beijing and almost 700,00 in Guangzhou. For the country as a whole, the number of vehicles in 1995 climbed to about 28 million (Michael Walsh).

With regard to driving patterns and average speeds, many existing roads have already reached their maximum capacity and are saturated during long period of each day.

Further, the vehicle technology being produced tends to be primarily carburetor equipped with mechanical rather than electronic controls. Many vehicles seem to be operating with a rich air fuel mixture which produces relatively good drivability, high fuel consumption, excess $\mathrm{CO}$ and HC but relatively low NOX emissions.

\section{Effect of Pollutants}

The vehicular pollutants have damaging effects on both human health and ecology. The human health effects of air pollution vary in the degree of severity, covering a range of minor effects to serious illness, as well as premature death in certain cases. These pollutants are believed to directly affect the respiratory and cardiovascular systems. In particular, high levels of Sulphur dioxide and Suspended Particulate Matter are associated with increased mortality, morbidity and impaired pulmonary function.

Carbon Monoxide: Affects the cardio vascular system, exacerbating cardiovascular disease symptoms, particularly angina; may also particularly affect fetuses, sick, anemic and young children, affects nervous system impairing physical coordination, vision and judgments, creating nausea and headaches, reducing productivity and increasing personal discomfort.

Nitrogen Oxides: Increased susceptibility to infections, pulmonary diseases, impairment of lung function and eye, nose and throat irritations.

Sulphur Dioxide: Affect lung function adversely.

Particulate Matter and Respirable Particulate Matter (PM and RPM): Fine particulate matter may be toxic in itself or may carry toxic (including carcinogenic) trace substance, and can alter the 
immune system. Fine particulates penetrate deep into the respiratory system irritating lung tissue and causing long-term disorders.

Lead: Impairs liver and kidney, causes brain damage in children resulting in lower I.Q., hyperactivity and reduced ability to concentrate. Benzene is both toxic and carcinogenic. Incidence of leukemia is found in high benzene exposure areas.

\section{Conclusion}

The problem of vehicular emissions is more severe by the fact that the pollutants are emitted at ground level which is in close proximity to the breathing zones of people. It contributes to ambient concentrations of pollutants such as carbon monoxide, oxides of nitrogen and sulphur, and particulates. At sufficiently high concentrations, these pollutants can cause health problems as well as degrade the environment and quality of life. In particular, diesel-driven vehicles emit particulates that are very fine and a large proportion of them are less than 2.5 microns in size. These fine particulates are generally known as PM2.5 and they can penetrate the deeper recesses of our lungs and cause respiratory problems. Studies in the US and other countries have linked PM2.5 to an increase in respiratory diseases and increased mortality. Epidemiological findings have shown that it is prudent to keep PM2.5 level to as low a level as possible in order to protect the health of the population.

In order to address the issues, there is a strong need of a detailed study on vehicular pollution as well as means to predict the individual \& combined effect of various parameters contributing to the increase of pollution in Kathmandu Valley.

\section{REFERENCES}

1. Ale, BB, 'The Role of Inspection and Maintenance Program in Controlling Vehicular Emission in Kathmandu Valley', Journal of the Institute of Engineering, vol. 4, 2004

2. CBS, Central Bureau of Statistics, 2001

3. Crouse, W.H. and Anglin, D.L., 2004, “Automotive Mechanics” Tenth Edition, Tata McGraw-Hill, New York, ISBN 0-07-059054-0

4. Department of Transport, 2007, Government of Nepal

5. Fiaz A. 2000, "New Direction: Road Traffic in Developing Countries" Journal of Atmospheric Environment, Vol. 34, pp.4745-4746.

6. NEA, Overview on control of vehicular smoke emission in Singapore, available at, http://app.nea.gov.sg/cms/htdocs/article.asp?pid=1509, retrived on Dec 18, 2007

7. Pulkrabek, W.W., 2002, "Engineering Fundamentals of the Internal Combustion Engine", Prentice Hall of India, ISBN 81-203-2222-3

8. Sapkota, BK, 'Air Pollution Transport from Kathmandu Valley', Journal of the Institute of Engineering, vol. 3, 2003

9. Singh, R.B. and Bhattarai, N.,2006, "Development of Liquid Bio-fuel out of the Traditional Biomass Resources to Generate Renewable fuel for Rural Development in Nepal”, RETRUD-06, pp.147-152. 